\title{
POTENTIAL OF MULTI-TEMPORAL INSAR TECHNIQUES FOR STRUCTURAL HEALTH MONITORING
}

\author{
Lazecky, M. ${ }^{(1,2)}$, Bakon, M. ${ }^{(2,3)}$, Sousa, J. J. ${ }^{(2,4)}$, Perissin, D. ${ }^{(5)}$, Hlavacova, I. $^{(2,6)}$, Patricio, G. ${ }^{(7,8)}$, Papco, J. ${ }^{(3)}$, \\ Rapant, P. ${ }^{(1)}$, Real, N. ${ }^{(9)}$ \\ (1) IT4Innovations, VSB-TU Ostrava, 17. listopadu 15, 70800 Ostrava-Poruba, Czech Republic, Email: \\ milan.lazecky@vsb.cz,petr.rapant@vsb.cz \\ (2) Universidade de Tras-os-Montes e Alto Douro, UTAD, Quinta de Prados, 5000-801 Vila Real, Portugal, Email: \\ jjsousa@utad.pt \\ (3) Department of Theoretical Geodesy, Slovak University of Technology, Radlinskeho 11, 81368 Bratislava, Slovakia, \\ matus.bakon@stuba.sk,juraj.papco@stuba.sk \\ (4) INESC TEC - INESC Technology and Science (formerly INESC Porto) \\ ${ }^{(5)}$ School of Civil Engineering, Purdue University, 550 Stadium Mall Drive, West Lafayette, IN47907, Office: HAMP \\ 4106, USA; www.sarproz.com,Email: perissin@purdue.edu \\ ${ }^{(6)}$ Czech Technical University in Prague, Faculty of Civil Engineering, Thakurova 7, 16629 Praha 6, Czech Republic, \\ Email: hlavacova@insar.cz \\ (7) Research Unit for Inland Development, Polytechnic Institute of Guarda, Av. Dr. Francisco Sa Carneiro $n^{\circ} 50$, \\ 6300-559 Guarda, Portugal, Email: gpatricio@ipg.pt \\ ${ }^{(8)}$ Departamento de Geociencias, Ambiente e Ordenamento do Territorio, Universidade do Porto, Portugal \\ (9) Consultores de Engenharia Norvia, SA Vila Real, Portugal,www.norvia.pt,Email: n.real@norvia.pt
}

\begin{abstract}
In this paper it is clearly demonstrated that InSAR techniques may be particularly useful as a hot spot indicator of relative structures deformation over large areas, making it possible to develop interferometric based methodologies for SHM. Different case studies from structural health monitoring of buildings, bridges and highways and dams in Slovakia, Czech Republic, Hong Kong and Portugal processed within the scope of "RemotWatch - Alert and Monitoring System for Physical Structures" project using non-linear and other SHM-optimized algorithms of SARPROZ software, are reported. For the future investigation it is expected, that due to the faster product delivery of new missions (e.g. SENTINEL-1), it will be possible to deliver new workflows suitable for near-real time analysis aimed to better understanding of the deformation characteristics of the structures in urban and extra urban areas, important for structure stability and risk management applications.
\end{abstract}

\section{INTRODUCTION}

By applying multi-temporal InSAR techniques to a series of satellite SAR images over the same region, it is possible to detect movements of the structure systems on the ground in the millimeter/centimeter range and, therefore, to identify abnormal or excessive movement indicating potential problems requiring detailed ground investigation. The wide variety of currently available spaceborne SAR sensors allows for the use of different frequencies and spatial resolutions. Results from multiple systems operating at different frequencies will often reveal different features. Furthermore, the repeat-pass nature and different system characteristics give rise to the low coherence due to geometrical and temporal decorrelation in some areas. The success and performance of InSAR technology for structural health monitoring (SHM) is then questionable. To achieve a complete knowledge framework on the performance of InSAR in SHM we highlight the differences in exploiting of various sources of the data (ERS, ENVISAT, TerraSAR-X, COSMO-SkyMed) especially for small scale analysis as there are some unexplored circumstances regarding scattering mechanism over the objects with different dimensions, geometry, orientation, material and the amount of displacements that could cause aliasing and others. In this work we also address the fact that we often work with limited or unequally sampled data stacks which, together with unfavourable environmental conditions and non-linear or seasonal components of movements, negatively affect proper parameter estimation using standard PSInSAR algorithm. The main improvement achieved using PSInSAR technique was that uniform deformation at low rates could more accurately be assessed. However, the standard PSInSAR algorithm is typically not successful in observing higher deformation rates or non-uniform deformations. In the case of information gaps for low-coherence areas or the difficulty to resolve high-phase gradients a non-linear model for retrieving deformation signal has to be searched for. Moreover, thanks to the large dataset of frequently acquired high resolution SAR data (e.g. TerraSAR-X, COSMO-SkyMed), it is possible to properly discover various types of deformation movements. Due to their 
very high sensitivity, the influence of some seasonal deformation sources, such as local temperature or water level changes, can more precisely be estimated. Finally, with a proper approach based partially on the model assumptions, the detected deformations or movements of structures in direction of satellite line of sight can be better decomposed into its horizontal and vertical direction components.

\section{CASE STUDIES OF BUILDINGS}

As it was researched by the standard PSInSAR methodology with the linear model assumption, the investigated urban area of Bratislava is stable stable with the linear deformation rates around noise level ( $+-3 \mathrm{~mm} /$ year) [1]. However, the adoption of non-linear deformation model of SARPROZ [2] reveals small movements on the structures without prior interest of any particular monitoring technique.

The example of a non-linear movemement detected by PSInSAR is shown in Figure 1. The depicted building is situated in the city centre near the Falkensteiner Hotel. The construction works on the hotel started in September, 2007. From results of both ascending and descending ENVISAT's tracks, it was concluded that works on a hotel affected the stability of this building by the subsidence of up to $-20 \mathrm{~mm}$.

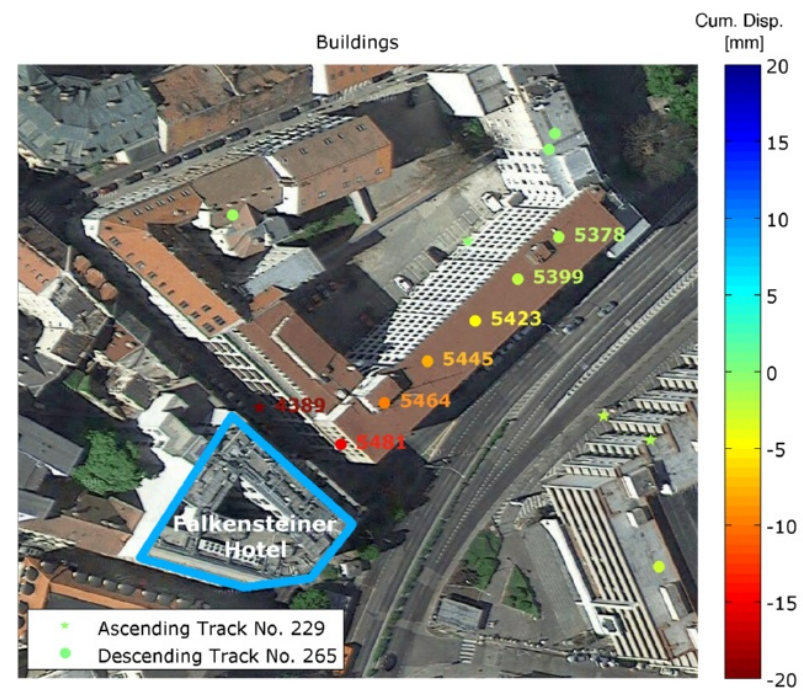

Figure 1. Envisat PS InSAR monitoring result of a building in Bratislava affected by digging of a construction pit for a nearby hotel in September 2007

Figure 2 reveals displacement analysis over the highrise building of the Hyatt Hotel in Hong Kong. The basement of the hotel structure looks stable, while the building facade is affected by the thermal expansion and by a slow constant displacement trend. Both displacement components are increasing with the building height. This is expected for what about the thermal expansion. An increasing linear displacement trend is on the contrary revealing an unexpected phenomenon. The only reasonable explanation is a horizontal movement, which corresponds to a slow tilting of the building. The top of the structure reveals 2 $\mathrm{mm}$ /year displacement in the satellite viewing direction, more than $3 \mathrm{~mm} /$ year if projected in the horizontal direction [1]
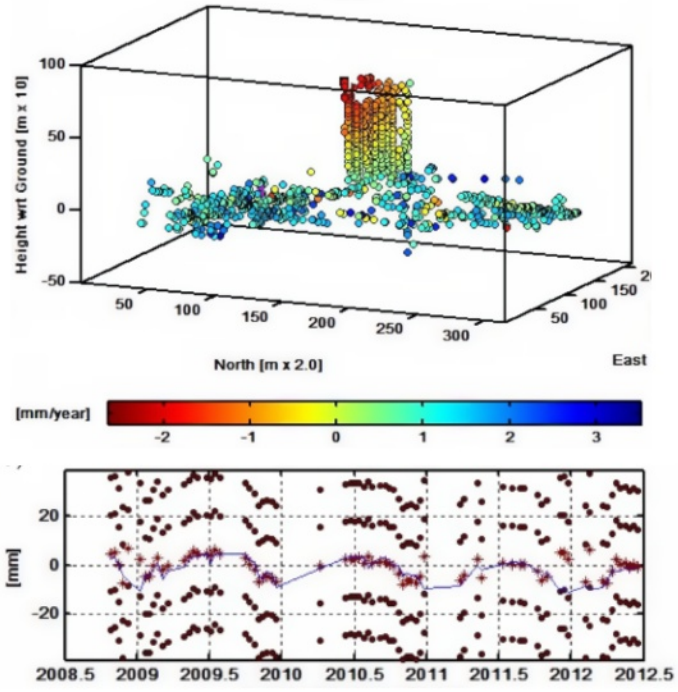

Figure 2. 3D representation of displacements of Hyatt Hotel estimated using PS InSAR, displacement time series include also thermal expansion component

\section{CASE STUDIES OF BRIDGES AND ROADS}

On 5th Sep 2014, two highway ramps were closed for vehicles over 3.5 tons in Ostrava city, due to alarming state of road between those ramps due to subsidence. This was clearly detected from PS InSAR processing results shown at Figure 3 . Using precise data of highway surface temperature, the phase changes over the ramps (bridges) were appointed as correlation with temperature $\left(\mathrm{K}_{\mathrm{temp}}\right)$ clearly estimated from the input data (15x TerraSAR-X images from 10/2013-02/2015) that cover minimal period of one full year cycle needed to distinguish $\mathrm{K}_{\text {temp }}$ from movements in time [3].

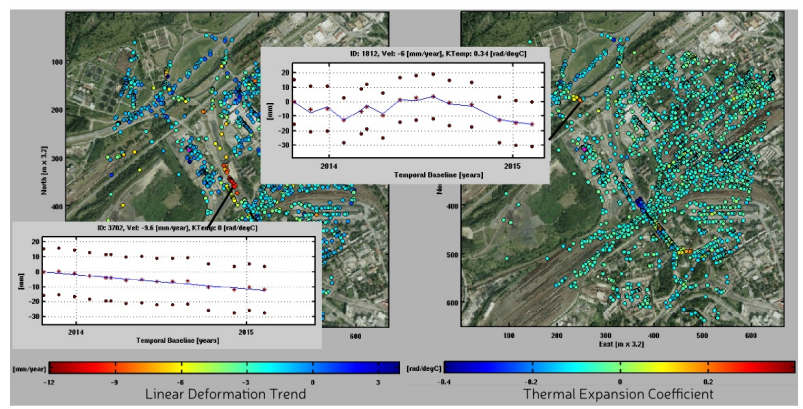

Figure 3. Linear deformation trend and thermal expansion coefficient of Ostrava-Trebovice road affected by subsidence, estimated from 15 TerraSAR-X images cover full year cycle

Radotinsky bridge is the longest bridge in Czech 
Republic (2281 m). It crosses valley above confluence of Vltava and Berounka rivers, that is prone to frequent flooding. Since 2010, enlarging cracks in welding of metal parts are monitored. 22 staring spotlight TerraSAR-X images detect non-linear movements highly correlated with temperature - see Figure 4 [4]. Following residual analysis detected, however, other non-linear influences that could be caused by bridge load, atmosphere inhomogeneties, non-linear thermal dilatio (possibly due to cracks) or simply inaccuracy in applied temperature values.

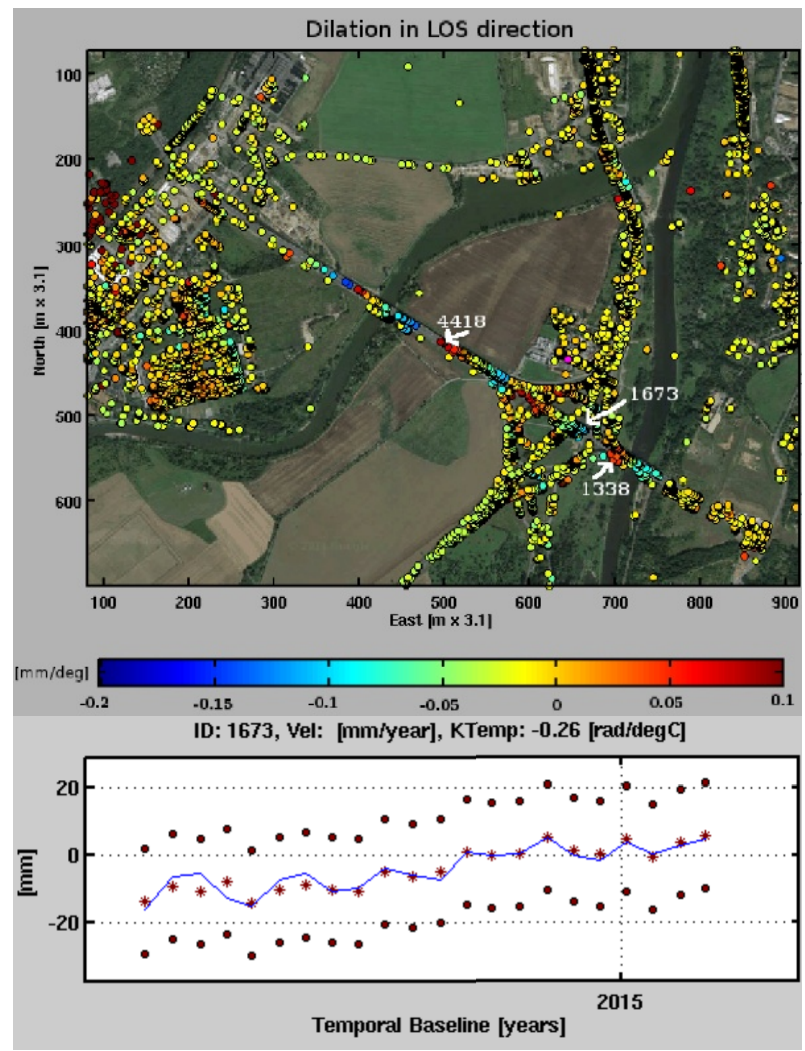

Figure 4. Thermal dilation effect of $2 \mathrm{~km}$ Radotinsky bridge monitored by PS InSAR processing of 22 Staring Spotlight TerraSAR-X images

\section{CASE STUDIES OF DAMS}

Figures 5 and 6 demonstrate results from Plover Cove dam (Hong-Kong) monitoring using TerraSAR-X dataset of 73 images [5]. High correlation with water level data was evaluated as a major cause of detected displacements. The dam is affected by very shallow but continuous subsidence almost homogeneously throughout its body (with higher rate on the side to the reservoir) and by higher rate of movements corresponding to water level changes, at the sides of the dam. Residual phase show correlation also with tidal changes of bay surrounding the dam - this component is however minor [6].

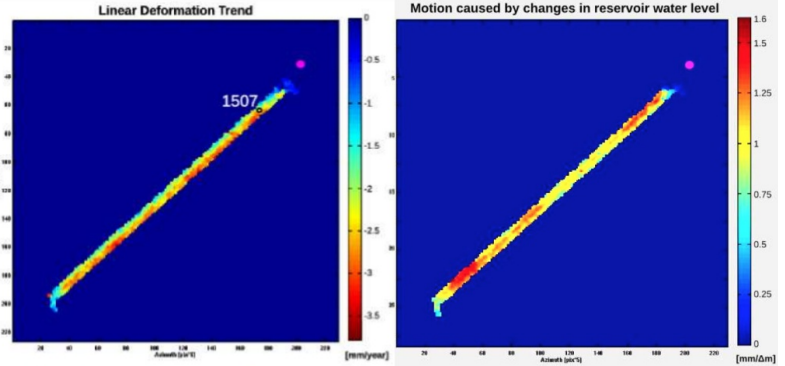

Figure 5. Coefficients of linear relation between LOS displacement and time (left) and water level of reservoir (right)

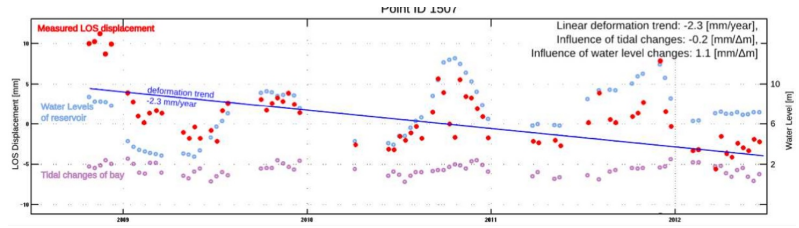

Figure 6. Example of data series of selected point after height estimation and recomputation of wrapped phase into LOS displacement [mm]: the correspondence of

LOS displacement with changes in water levels is obvious

Paradela dam in Portugal shows at Figure 7 a linear deformation trend in top-center part. It is expected to be horizontal, therefore the detected movements can be recomputed from radar LOS into horizontal direction using Eq. 1 as up to $-12.1 \pm 2.5 \mathrm{~mm} /$ year for point 117 (corresponding to LOS value of $-3.6 \pm 0.7 \mathrm{~mm} /$ year) [7].

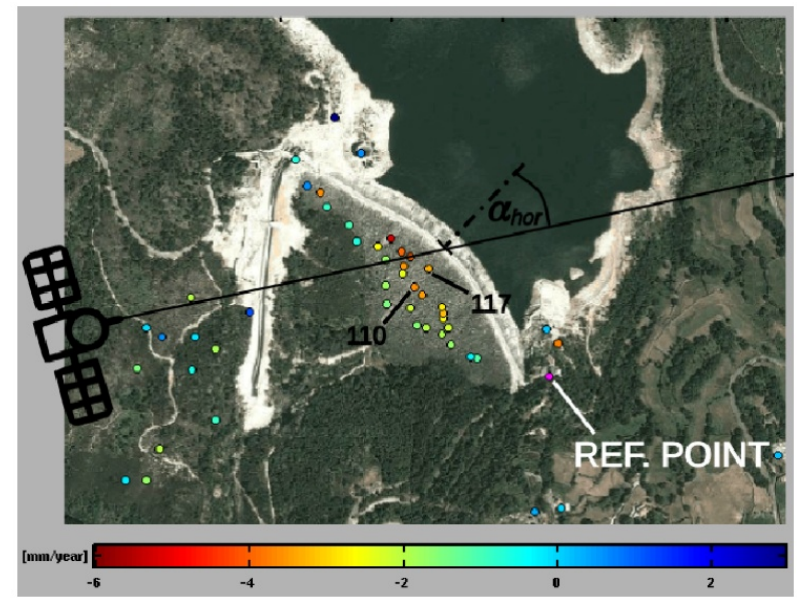

Figure 7. PS InSAR deformation trend result of

Paradela dam monitoring using 14 Envisat images from 10/2002-05/2007

$\mathrm{D}_{\text {hor }}=\mathrm{D}_{\mathrm{LOS}} /\left(\sin \theta_{\text {inc }} \cdot \cos \alpha_{\text {hor }}\right)$

, where $\mathrm{D}_{\text {LOS.. }}$ deformation in LOS, $\mathrm{D}_{\text {hor. }}$ deformation in direction of dam axis, $\theta_{\text {inc.. }}$ SAR incidence angle, $\alpha_{\text {hor. }}$. horizontal angle between LOS and dam axis. 


\section{CONCLUSIONS}

There are many ways to monitor the structural health of constructions, such as bridges or dams. Contact (sensor) methods do make it possible to monitor strain, tilt, vibration and other features very sensibly, however only at selected points where they are located. For newly built bridges, these sensors may be connected in a monitoring system, with the possibility to remotely evaluate e.g. the reaction of the construction to a loading in real time. The most significant advantage of such methods is its sensibility and the possibility to monitor the most critical points of the construction. However, for already built constructions, these methods are a bit cumbersome.

Among the traditional geodetic surveying techniques for measuring the deformation of man-made structures, the levelling is able to perform high precision in measuring the vertical component of deformation under unfavorable environmental conditions where other techniques cannot be used. It can bring cost-effectiveness when global inspection of structure together with surrounding area takes place.

The other methods mentioned are typically non-contact, except for GNSS. The GNSS method requires the placement of few GNSS receivers, typically on the top deck of the bridge/dam construction, allowing to monitor movements in 3D. Accuracy of such movements is much better in horizontal plane than in the vertical direction, which makes the method not suitable for loading tests; however, it is suitable for bridge/dam deflection monitoring. However, the deformation information is again only for separated points. In addition, it is necessary to ensure a good visibility between the receiver and satellites (if there are trees etc. in the path, the accuracy is worsening).

Airborne methods (photogrammetry and LiDAR) require an aircraft flight, which may be costly and it is possible only in good weather conditions. However, more constructions can be scanned during one flight, reducing the cost. LiDAR provides a huge cloud of very good resolution data, making it possible even to see cracks in the construction. However, the airborne methods usually monitor only the top deck of the construction, even if they scan the bridge/dam from the side, the look angle does not provide for a good accuracy. In addition, both methods are aimed to visible defects. These methods are not suitable for loading tests. Ground-based methods require one or two standpoints at the bottom of the bridge/dam, allowing to scan the side of the bridge or the whole dam. Its cost depends directly on the number of epochs performed, and each epoch can be processed separately to give meaningful results. All methods except for GB-SAR require good visibility, while GB-SAR, on the other hand, gives radar artefacts near bridge cables or other metal parts. All methods are suitable for loading tests, some of them even for the dynamic tests (depends on the instrument). Spaceborne InSAR, similarly to airborne methods, monitors usually the top-deck of the bridge/dam (similarly to airborne methods, monitoring the side is also possible, but with worse accuracy). In addition, its accuracy depends on the construction orientation and number of scenes used, which may be a limiting factor. However, at the same cost it is possible to monitor all bridges in an area covered by a scene (depends on resolution), and as the only method, it has the possibility to map deformation even in the past, if scenes were acquired.

Monitoring methods have different features and are optimal in different situations. Airborne and spaceborne methods should be used for systematic monitoring of structural health of bridges, and in case of a suspicious results, more sensible/accurate methods should be used (visual inspection, loading tests for bridges with the use of sensors, ground-based methods, levelling), depending on the nature of the problem. Most of the methods are aiming at the movement of some part of the construction, which is probably a first outer sign of a structural problem; however, some sensor may recognize such a problem even if it can not be yet recognized by the other methods [8].

\section{ACKNOWLEDGEMENTS}

This work is partially supported by the European Fund for Regional Progress - FEDER (Fundo Europeu de Desenvolvimento Regional) through the project BI/COMPETE/38732/UTAD/2014: "RemotWatch Alert and Monitoring System for Physical Structures". This work was supported by the European Regional Development Fund in the IT4Innovations Centre of Excellence project (CZ.1.05/1.1.00/02.0070). This paper has been elaborated in the framework of the project New creative teams in priorities of scientific research, reg. no. CZ.1.07/2.3.00/30.0055, supported by Operational Programme Education for Competitiveness and co-financed by the European Social Fund and the state budget of the Czech Republic. This work is also the result of implementation of the project: the National Centre of Earth's Surface Deformation Diagnostic in the area of Slovakia, ITMS 26220220108 supported by the Research and Development Operational Programme funded by the ERDF and the grant No. 1/0642/13 of Slovak Grant Agency VEGA.

\section{REFERENCES}

1. Bakoň, M., Perissin, D., Lazecký, M., Papčo, J., 2014. Infrastructure Non-Linear Deformation Monitoring Via Satellite Radar Interferometry, in: Procedia Technology. Presented at the CENTERIS 2014, 15-17 Oct 2014, Troia, Portugal. doi: 10.1016/j.protcy.2014.10.095. 
2. Perissin, D. (2014). SARPROZ software. Official Product Web Page: www.sarproz.com

3. Lazecký, M., Perissin, D., Bakoň, M., Sousa, J. J. M., Hlaváčová, I., Real, N. (2015). Potential of satellite InSAR techniques for monitoring of bridge deformations. In: JURSE Lausanne, 30.3.-1.4.2015, 4 pp.

4. Hlavacova, I., Kolomaznik, J., Halounova, L. (2015). TerraSAR-X Staring Spotlight Monitoring of a Highway Bridge in the Czech republic, In: Fringe 2015 Workshop, 23-27 March 2015, Frascati.

5. Lazecký, M., Perissin, D., Scaioni, M., Lei, L., Qin Y. (2013). Plover Cove Dam Monitoring with Spaceborne InSAR Technique in Hong Kong. In: 2nd JISDM 2013, 9-10 Sep 2013, Nottingham.

6. Lazecký, M., Perissin, D., Zhiying, W., Ling, L., Yuxiao, Q. (2014). Observing Dam's movements with spaceborne SAR interferometry, Engineering Geology for Society and Territory - Vol. 5, Part III, pp 131-136, Springer Int. Switzerland, DOI 10.1007/978-3-319-09048-1_26,

ISBN 978-3-319-09047-4.

7. Sousa, J. J. M., Lazecký, M., Hlaváčová, I., Bakoň, M., Patricio, G., Perissin, D. (2015). Satellite SAR Interferometry for Monitoring Dam Deformations in Portugal. In: Dam World 2015, Lisbon.

8. Sousa, J. J., Hlaváčová, I., Bakoň, I., Lazecký, M., Patrício, G., Guimarãese, P., Ruiz, A. M., Bastosi, L., Sousa, A. (2014). Potential of Multi-Temporal InSAR for Bridges and Dams Monitoring. In: CENTERIS 2014, 15-17 Oct 2014, Troia, Portugal. doi:10.1016/j.protcy.2014.10.033 